\title{
Nuclear receptor-like transcription factors in fungi
}

\author{
Anders M. Näär ${ }^{2}$ and Jitendra K. Thakur ${ }^{1}$ \\ Massachusetts General Hospital Cancer Center and Department of Cell Biology, Harvard Medical School, Charlestown, \\ Massachusetts 02129, USA
}

\begin{abstract}
Members of the metazoan nuclear receptor superfamily regulate gene expression programs in response to binding of cognate lipophilic ligands. Evolutionary studies using bioinformatics tools have concluded that lower eukaryotes, such as fungi, lack nuclear receptor homologs. Here we review recent discoveries suggesting that members of the fungal zinc cluster family of transcription regulators represent functional analogs of metazoan nuclear receptors. These findings indicate that nuclear receptor-like ligand-dependent gene regulatory mechanisms emerged early during eukaryotic evolution, and provide the impetus for further detailed studies of the possible evolutionary and mechanistic relationships of fungal zinc cluster transcription factors and metazoan nuclear receptors. Clinical implications of the discovery of nuclear receptor-like transcription factors in pathogenic fungi will also be discussed.
\end{abstract}

All organisms are challenged by rapid changes in their environment and a key to adaptation and survival has been the evolution of mechanisms to rapidly sense and respond to environmental cues. For example, nutritional homeostasis is essential to organism well-being and changes in the supply or quality of nutrients consequently may pose immediate and severe consequences that must be adjusted to swiftly to avoid malnutrition or death. Cells and organisms also need to rapidly sense environmental toxic challenges or the toxic accumulation of endogenous metabolic by-products and elicit a coordinated detoxification response. Accordingly, many different types of cellular sensors and effectors have evolved to monitor and respond to changing environmental conditions as well as metabolic imbalances.

In metazoans, the nuclear receptor superfamily of transcription factors are direct effector signaling sensors that typically bind and respond to small lipophilic molecules to regulate gene expression programs that govern numerous physiologically important processes, including

[Keywords: Nuclear receptor; zinc cluster transcription factor; multidrug resistance; Mediator; Gall1p; KIX domain]

${ }^{1}$ Present address: IISER Kolkata, IIT Kharagpur Extension Centre, Block-HC, Sector-III, Salt Lake City, Kolkata 700106, India.

${ }^{2}$ Corresponding author.

E-MAIL naar@helix.mgh.harvard.edu; FAX (617) 726-7808.

Article is online at http://www.genesdev.org/cgi/doi/10.1101/gad.1743009. development, reproduction, aging, and metabolism. Members of the nuclear receptor superfamily share common domain architecture, including a highly conserved zinccoordinating DNA-binding domain and a structurally conserved ligand-binding domain. Nuclear receptors were first identified as steroid and thyroid hormone receptors and were initially thought to serve solely as endocrine signal transducers (Mangelsdorf et al. 1995). Subsequent work based on DNA sequence similarity with steroid receptors revealed a number of "orphan" nuclear receptors; i.e., receptors for which ligands were unknown. Many of these orphan receptors have now been found to bind and respond to environmental as well as endogenous small molecules and metabolites, including vitamin derivatives and diverse cellular metabolites, such as vitamin D3, retinoids (derived from vitamin A), fatty acids, cholesterol derivatives, heme, sugars, as well as environmental toxins and endogenous toxic metabolites (Luisi et al. 1994; Mangelsdorf et al. 1995; Moras and Gronemeyer 1998; Peet et al. 1998; Desvergne and Wahli 1999; Parks et al. 1999; Kliewer et al. 2001, 2002; Willson and Kliewer 2002; Handschin and Meyer 2005; Reinking et al. 2005; Mitro et al. 2007; Raghuram et al. 2007; Yin et al. 2007).

Bioinformatics analyses as well as genetic studies have revealed the presence of a large family of nuclear receptors in metazoans. The human genome encodes for 48 nuclear receptors, Drosophila has 21 nuclear receptor genes, whereas the nematode Caenorhabditis elegans harbors a large number $(>280)$ of genes encoding nuclear receptors (Maglich et al. 2001; Robinson-Rechavi and Laudet 2003; Bertrand et al. 2004; Escriva et al. 2004). Sequence analyses based on the conservation of the zinc finger DNA-binding domain and the ligand-binding domain have suggested that nuclear receptors arose during metazoan evolution, and that there are no orthologs present in fungi and plants (Owen and Zelent 2000; Robinson-Rechavi and Laudet 2003; Bertrand et al. 2004; Escriva et al. 2004). Moreover, the conclusion is also drawn that the nuclear receptors gained ligandbinding ability during subsequent stages of evolution (Escriva et al. 2000, 2004).

Although fungi and plants do not harbor nuclear receptor orthologs based on sequence analysis, it is interesting to note that the transcriptional activities of 
members of the fungal binuclear zinc cluster transcription factor family are also modulated by small molecules, including environmental chemicals, nutrients, and cellular metabolites (Reece 2000; Sellick and Reece 2005; MacPherson et al. 2006). In this review, we highlight recent findings indicating functional analogy of several fungal zinc cluster transcription factors with metazoan nuclear receptors, as well as overall organizational/functional similarities between these families of small moleculeregulated transcription factors. We will discuss the implications of the discovery of nuclear receptor-like gene regulatory pathways in fungi for our understanding of signaling mechanisms guiding conserved biological pathways in eukaryotes and their potential biomedical impact.

\section{General architectural and functional similarities between metazoan nuclear receptors and fungal zinc cluster transcription factors}

While there is no apparent sequence or structural similarity of nuclear receptors and fungal zinc cluster transcription factors, we note here interesting general architectural and functional similarities of these large families of gene regulators (Fig. 1; Luisi et al. 1994; Mangelsdorf et al. 1995; Todd and Andrianopoulos 1997; Moras and Gronemeyer 1998; Reece 2000; Sellick and Reece 2005; MacPherson et al. 2006). Although the protein sequences and structural folds of fungal zinc clusters and nuclear receptor zinc fingers are clearly distinct, both types of DNA-binding domains are composed of cysteines (six cysteines for zinc clusters versus four cysteines in each of the two fingers for nuclear receptors) coordinating two zinc ions (Krishna et al. 2003). The fungal zinc cluster DNA-binding domain is a single domain structure that targets both the major groove of the DNA-binding site and the phosphate backbone (Schwabe and Rhodes 1991; Todd and Andrianopoulos 1997). The nuclear receptor zinc finger DNA-binding domain also interacts with the major groove and phosphate backbone of DNA-binding sites, but additionally contributes to dimerization and determination of DNA halfsite spacing preference (Freedman and Luisi 1993). Similar to fungal zinc cluster DNAbinding domains, and consistent with their functional interdependence, the two-nuclear receptor $\mathrm{Cys}_{2}-\mathrm{Cys}_{2}$ zinc fingers also appear to have coevolved as part of a single, integrated domain (Krishna et al. 2003). In contrast, the classical $\mathrm{Cys}_{2}-\mathrm{His}_{2}$ zinc fingers bind to DNA as independent units, and $\mathrm{Cys}_{2}-\mathrm{His}_{2}$ zinc finger DNA-binding domains have evolved by mixing and matching zinc fingers based on gene duplication to afford DNA-binding specificity (Krishna et al. 2003).

Because the DNA-binding domains of nuclear receptors and zinc cluster transcription factors have evolved as single structural units, they are structurally highly similar within families. This structural rigidity of the DNAbinding domains and the limited ability to alter sequences within the DNA-binding domains without compromising structural integrity raise the question as to how family members are able to regulate distinct sets of target

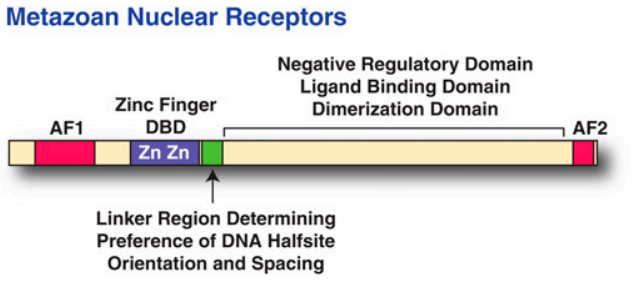

Fungal Zinc Cluster Transcription Factors

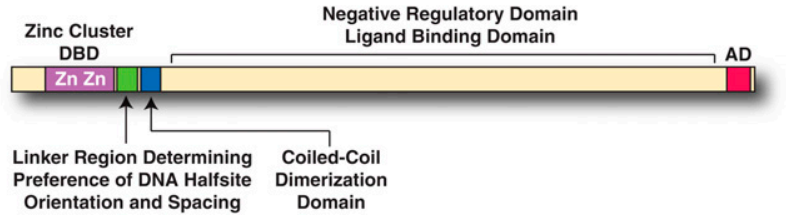

Figure 1. Comparison of canonical structural organization of metazoan nuclear receptors and fungal zinc cluster transcription factors. Despite a lack of obvious sequence and structural homology, metazoan nuclear receptors and yeast zinc cluster transcription factors exhibit a number of architectural and functional similarities. (Top) Metazoan nuclear receptors are characterized by a central or N-terminal DNA-binding domain (DBD) consisting of eight cysteines coordinating two zinc ions forming two zinc fingers (blue), followed by a linker region (green) that determines DNA halfsite spacing and orientation preference, a large C-terminal domain (bracket) that also contributes to homo- and heterodimerization among family members, as well as negative regulatory function in the absence of ligand, and ligand binding/response, followed by a short activation domain (red) in the distal C-terminal tip that mediates binding to transcriptional coactivators (AF2). The sequences C-terminal to the linker region typically form a 12-helix bundle structure that integrates these different functions. A number of nuclear receptors also exhibit an activation domain $\mathrm{N}$-terminal to the DNA-binding domain (AF1, red). (Bottom) Fungal zinc cluster transcription factors exhibit an $\mathrm{N}$-terminal zinc cluster DNA-binding domain consisting of six cysteines coordinating two zinc ions (purple), followed by a linker region (green) that determines DNA halfsite spacing and orientation preference, a coiled-coil dimerization domain (blue), a large C-terminal negative regulatory domain (bracket) that also contains sequences mediating ligand-binding/response, followed by a short activation domain (red) in the distal C-terminal tip that mediates binding to transcriptional coactivators ( $\mathrm{AD}, \mathrm{red})$.

genes. Interestingly, in addition to the alteration of a few discrete amino acids in the DNA-binding domains to promote DNA sequence specificity, both families of transcription factors appear to have evolved a similar mechanism based on dimerization to achieve distinct DNA-binding and regulatory specificity amongst family members. The majority of nuclear receptors and fungal zinc cluster transcription factors bind as homo- or heterodimers to DNA response elements organized as two core DNA recognition halfsites. This has allowed coevolution of dimer pairs with their cognate DNA elements, yielding DNA-binding specificity of highly related family members that is largely determined by distinct recognition of the orientation (direct, inverted, or everted) and nucleotide spacing of halfsites (Näär et al. 1991; Umesono et al. 1991; Kurokawa et al. 1993; Perlmann et al. 1993; Reece 
and Ptashne 1993; Hellauer et al. 1996; Noel and Turcotte 1998; MacPherson et al. 2006). Importantly, the linker regions just C-terminal to the DNA-binding domains contribute significantly to DNA-binding specificity within both transcription factor families by selecting spacing requirements between DNA recognition halfsites. Indeed, swapping linker regions between different nuclear receptor or zinc cluster family members switches the recognition of the target DNA sequence and gene regulatory specificity (Kurokawa et al. 1993; Perlmann et al. 1993; Reece and Ptashne 1993; Mamane et al. 1998). In both cases it has been suggested that the linker region provides a framework for establishing contact with a preferred DNA sequence and prevent binding to nonspecific sites. In zinc cluster transcription factors, following the linker region is a stretch of amino acids forming a coiledcoiled structure required for dimerization (Fig. 1; Schjerling and Holmberg 1996). The dimerization domain of nuclear receptors is primarily located in the sequences C-terminal to the DNA-binding domain as part of the 12-helix bundle structure and sequences participating in the dimer interface may also form a coiled-coil structure (Gampe et al. 2000). As mentioned above, there are also important contributions from interactions between nuclear receptor zinc fingers to both dimerization and DNA halfsite spacing specificity.

Located C-terminal to the linker/dimerization domains is a large negative regulatory domain, which for a number of members of both families mediates ligand binding or response to small molecules, such as cellular metabolites and lipophilic ligands (Fig. 1). This domain in nuclear receptors typically forms a canonical 12-helix bundle that generates a hydrophobic pocket accommodating lipophilic ligands (Weatherman et al. 1999). While there are currently no structural studies of the corresponding domain in zinc cluster transcription factors, they do harbor a conserved fungal-specific sequence within this domain (termed middle homology region; MHR), suggesting a common fold that might, based on its location within the small molecule-regulated inhibitory domain, relate to ligand-dependent gene regulation (Schjerling and Holmberg 1996). Mutations and deletions within this region frequently render zinc cluster transcriptional regulators constitutively active, consistent with it playing a role in restricting transactivation in the absence of activating cues (Balzi et al. 1987; Friden et al. 1989; Pfeifer et al. 1989; Delaveau et al. 1994). Mutations within the ligand-binding domain of nuclear receptors can also result in constitutively active proteins (Weis et al. 1996; Watkins et al. 2001), consistent with a similar role for sequences within the nuclear receptor ligand-binding domain in preventing ectopic gene activation by unliganded receptors.

Finally, most metazoan nuclear receptors and fungal zinc cluster transcription factors harbor short activation domains within the distal portion of the $\mathrm{C}$ terminus that mediate transactivation function through recruitment of transcriptional coactivators, as discussed below (Fig. 1). The activation domains are typically kept inactive in the absence of activating small molecules by the large nega- tive regulatory domain, and, in the case of several nuclear receptors, ligand binding has been shown to result in allosteric alterations relieving intramolecular inhibition (Glass and Rosenfeld 2000). In contrast with fungal zinc cluster transcription factors, which generally have a very short stretch of amino acids before the start of the DNAbinding domain, a number of nuclear receptors also harbor a constitutive activation domain (AF1) N-terminal to the DNA-binding domain (Fig. 1).

\section{Small molecule/ligand-independent association with corepressors}

In the absence of their cognate ligands, a number of nuclear receptors (e.g., thyroid hormone, retinoic acid, and vitamin $\mathrm{D}_{3}$ receptors) can interact via discrete sequences within the ligand-binding domain with corepressors, such as N-CoR and SMRT complexes that harbor histone deacetylases, and actively repress transcription of target genes by modulating the local chromatin environment (Glass and Rosenfeld 2000). Ligand binding to these nuclear receptors results in release of the corepressors, allowing recruitment of coactivators that facilitate gene activation as discussed below (Glass and Rosenfeld 2000). The association of nuclear receptors such as the thyroid hormone receptor with corepressors ensures that expression of target genes is very low in the absence of activating signals, and that ligand activation acts in a switch-like manner.

Although there are no apparent homologs of the $\mathrm{N}-\mathrm{CoR} / \mathrm{SMRT}$ corepressors in fungi, it is interesting to note that at least two yeast zinc cluster transcription factors, Pprlp and Haplp, interact with a fungal-specific corepressor (Tuplp/Ssn6p complex) in the absence of ligands, resulting in repression of target gene transcription (Patzold and Lehming 2001; Hickman and Winston 2007). The Leu3p zinc cluster transcription factor can also repress transcription of genes in the leucine biosynthesis pathway in the absence of stimulatory cues, while activating transcription in response to the leucine biosynthesis intermediate $\alpha$ isopropylmalate ( $\alpha$-IPM) (Kohlhaw 2003); however, it is not known whether Leu3p associates with corepressors in the absence of $\alpha$-IPM.

\section{Role of transcriptional coactivators in gene activation by nuclear receptors and zinc cluster transcription factors}

Transcription activators promote gene activation by binding to coactivators that facilitate chromatin remodeling and target gene access as well as the recruitment of components of the general transcriptional apparatus (Roeder 1998; Näär et al. 2001; Malik and Roeder 2005; Rosenfeld et al. 2006). Mechanistic studies of liganddependent transactivation by vertebrate nuclear receptors have identified a number of transcriptional coactivators that are typically recruited by nuclear receptors in a ligand-stimulated manner to mediate gene activation (Rosenfeld and Glass 2001; Nettles and Greene 2005; Rosenfeld et al. 2006). Several of these coactivators, including the p160 family (SRC1-3) and the TRAP220/ 
MED1 subunit of the Mediator complex, harbor Leucine$X$ - $X$-Leucine-Leucine (LXXLL, where $X$ is any amino acid) motifs (also known as NR boxes) that are directly targeted by the activation domains of ligand-bound nuclear receptors (Savkur and Burris 2004). Several nuclear receptors also recruit coactivators via their $\mathrm{N}$-terminal activation domains (Onate et al. 1998; Bevan et al. 1999; Kumar et al. 2001). While the role for these classes of coactivators in vertebrate nuclear receptor transcriptional control is well established, the coactivator requirements for gene activation by invertebrate nuclear receptors remain unclear. For example, while there is a single gene in Drosophila (taiman) distantly related to p160 proteins (Bai et al. 2000), there are no apparent homologs of the p160 coactivators in C. elegans (our unpublished analysis), and the TRAP220/MED1 Mediator subunits in fruitflies and nematodes lack LXXLL motifs, raising the question as to how nuclear receptors activate transcription in these organisms.

Interestingly, C. elegans NHR-49, an orphan nuclear receptor proposed to function similarly to mammalian Peroxisome Proliferator-Activated Receptor $\alpha(\operatorname{PPAR} \alpha)$, was found to interact with the C. elegans Mediator subunit MDT-15 and to require MDT-15 for regulation of genes involved in fatty acid and glucose homeostasis (Taubert et al. 2006). Moreover, a recent study found that MDT-15 also appears to be involved in a detoxification response pathway in C. elegans (Taubert et al. 2008), indicating the possibility that a xenobiotic-activated nuclear receptor homologous to vertebrate Pregnane X Receptor (PXR) in this metazoan might also utilize the conserved MDT-15 subunit as a coactivator target.

Intriguingly, similar to C. elegans NHR-49, several fungal zinc cluster transcription factors, including the galactose-regulated Gal4p, the xenobiotic-activated Pdr1p orthologs, and the fatty-acid-responsive Oaflp, interact with and require the yeast MDT-15 homolog Gall1p/MED15 as a critical coactivator to mediate ligand-dependent gene activation (Suzuki et al. 1988; Jeong et al. 2001; Reeves and Hahn 2005; Thakur et al. 2008a,b). Gal11p/MED15 harbors an activator-targeted KIX domain with structural and functional similarity to the mouse CBP and human ARC105/MED15 KIX domains and the C-terminal activation domains of Pdrlp orthologs and Oaflp bind to the Gal11p/MED15 KIX domain in a ligand-stimulated manner, and the KIX domain plays a critical role in ligand-dependent gene activation by these activators (Radhakrishnan et al. 1997; Yang et al. 2006; Thakur et al. 2008a,b). In contrast, the Med1p/MED1 Mediator subunit, which in mammals serves as an important nuclear receptor coactivator, does not appear to play any role in ligand-dependent transactivation by these transcription factors (Thakur et al. 2008a,b). Moreover, fungi appear to lack p160 homologs (our unpublished analysis), revealing a specific and unique role for Gal11p/MED15 in these fungal nuclear receptor-like signaling pathways.

These findings, together with the NHR-49 data discussed above, suggest that the targeting of the KIX domain of MED15 orthologs in fungi and nonvertebrate metazoans might represent a primordial transactivation mechanism by certain ligand-stimulated transcription factors, predating the evolution of the LXXLL-containing coactivators as nuclear receptor targets in higher eukaryotes.

\section{Functional analogs of nuclear receptors in fungi}

In this section, we highlight data from several recent studies suggesting that certain fungal zinc cluster transcription factors function a in a manner analogous to metazoan nuclear receptors.

\section{Mechanistic analogies of xenobiotic-dependent regulation of multidrug resistance (MDR) in fungi and vertebrates}

MDR, a phenomenon defined as the ability of cells to acquire resistance to a wide range of structurally and functionally distinct cytotoxic or cytostatic compounds, is often caused by overexpression of drug efflux pumps resulting in the expulsion of a wide variety of molecules, and presents a major obstacle in the treatment of infectious disease caused by bacterial and fungal pathogens (Piddock 2006; Sipos and Kuchler 2006). In humans, acquired MDR in tumor cells hampers cancer chemotherapy and is frequently resulting from amplification and/or increased expression of members of the P-glycoprotein family of ATP-binding cassette (ABC) drug transporters (Deeley et al. 2006; Szakacs et al. 2006). The vertebrate nuclear receptor PXR, together with its heterodimer partner Retinoid X Receptor (RXR), up-regulates transcription of members of the P-glycoprotein family, as well as cytochrome P450 (CYP450) detoxification enzymes in response to direct binding to chemically diverse drugs and xenobiotics (Fig. 2; Kliewer et al. 2002). The nuclear receptor family member Constitutive Androstane Receptor (CAR) has also been implicated in xenobioticdependent regulation of CYP450 enzymes (Willson and Kliewer 2002).

Recent studies have revealed that orthologs of the Pdrlp zinc cluster transcription factor in Saccharomyces cerevisiae and in the important human opportunistic pathogen Candida glabrata exhibit functional characteristics that are strikingly similar to mammalian PXR (Fig. 2). Pdrlp orthologs have been described as master regulators of the MDR network in fungi and confer resistance to antifungal drugs and toxins through transcriptional activation of $\mathrm{ABC}$ transporter genes such as PDR5 and $S N Q 2$, as well as members of the major facilitator superfamily (MFS) of drug transporter (Katzmann et al. 1994; Balzi and Goffeau 1995; Carvajal et al. 1997; Rogers et al. 2001; Moye-Rowley 2003). Importantly, azole antifungals and other xenobiotics promote transcriptional stimulation of genes encoding drug efflux pumps, and Pdrlp orthologs were shown to be required for this effect (Gao et al. 2004; Mamnun et al. 2004; Vermitsky and Edlind 2004; Lucau-Danila et al. 2005; Alenquer et al. 2006; Tsai et al. 2006; Vermitsky et al. 2006); however, the xenobiotic signaling pathway was not further delineated. Intriguingly, a recent study showed that Pdrlp 
A

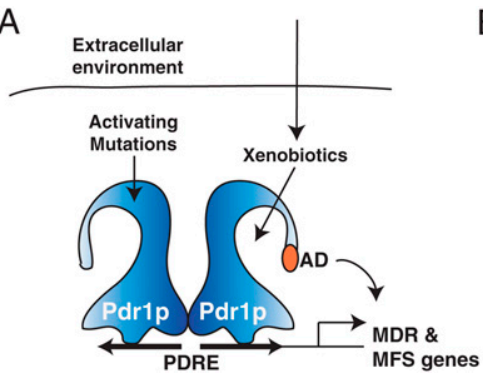

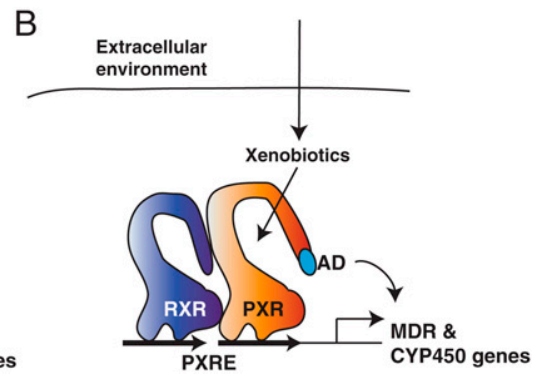

Figure 2. Pdrlp orthologs are xenobiotic receptors functionally analogous to the mammalian nuclear receptor PXR. Cartoon depicting a comparison of the functional similarities of the fungal zinc cluster transcription factor Pdrlp $(A)$ with the mammalian xenobiotic receptor PXR and its heterodimer partner RXR $(B)$. Pdrlp orthologs and paralogs were initially identified based on activating mutations in their negative regulatory domains that cause constitutive activation of genes involved in MDR, but have recently been shown to directly interact with xenobiotics to activate gene transcription and are thus functionally analogous to PXR. orthologs in S. cerevisiae and C. glabrata bind directly to structurally unrelated drugs and xenobiotics, and, as a result, activate the expression of genes encoding ATPdependent drug efflux pumps (e.g., P-glycoprotein/MDR1 orthologs), contributing to MDR that impedes treatment of fungal infections (Fig. 3; Goffeau 2008; Thakur et al. 2008a). This functional behavior is thus analogous to the action of the vertebrate PXR xenobiotic receptor (Kliewer et al. 2002).

As discussed above, Pdrlp orthologs require the Mediator subunit Gal11p/MED15 and its KIX domain for xenobiotic-dependent gene activation and MDR in $S$. cerevisiae and C. glabrata (Fig. 3; Thakur et al. 2008a). Moreover, xenobiotics significantly promote the interaction of Pdrlp with the Gal11p/MED15 KIX domain in vitro and in vivo, suggesting a nuclear receptor-like gene activation mechanism whereby ligand binding relieves intramolecular inhibition allowing coactivator recruitment by the transactivation domain.

Whereas many nuclear receptors (e.g., steroid and thyroid hormone receptors) bind to specific ligands with high affinity (pico-nanomolar range), the PXR ligandbinding domain exhibits the unusual capability of directly binding xenobiotics of diverse chemical nature via relatively low-affinity (nanomolar-micromolar) interactions (Kliewer et al. 2002; Chang and Waxman 2006). In contrast with the apparent specificity of other zinc cluster transcription factors for small-molecule activators (e.g., Leu3p/ $\alpha$-IPM, Put3p/proline and proline analogs, and Haplp/heme; Sellick and Reece 2005), and similar to PXR, Pdrlp orthologs bind to several structurally unrelated chemicals in a functionally productive manner to activate transcription of target genes. Indeed, this relative lack of ligand specificity is key to the ability of PXR and Pdrlp orthologs to "survey" the accumulation of a large number of chemicals in the cell and mount a detoxification response when levels reach toxic thresholds unique to each chemical. The toxicity thresholds are likely determined specifically for each organism by natural selection depending on the spectrum of toxic challenges found in each environmental niche. Consistent with this idea, mouse PXR responds to a selection of

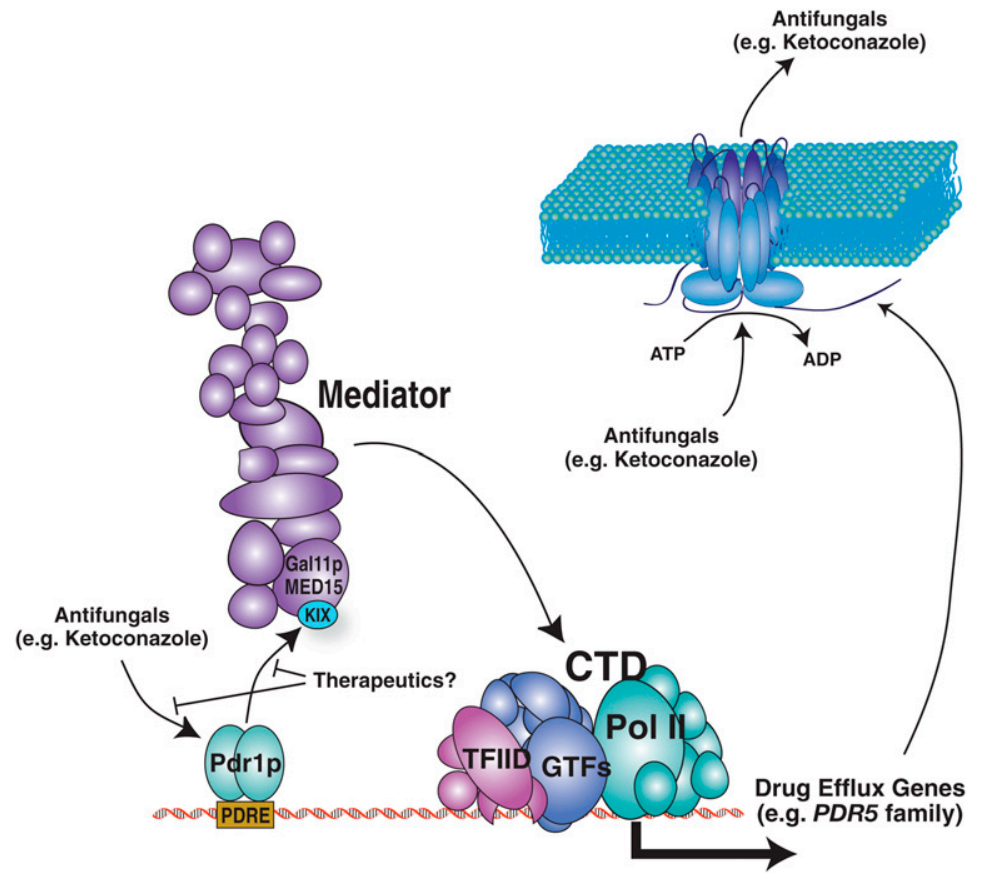

Figure 3. Cartoon depicting hypothetical model of xenobiotic-dependent gene regulation of drug efflux pumps by Pdrlp orthologs in fungi. Pdrlp orthologs control the expression of genes encoding drug efflux pumps (e.g., $\mathrm{ABC}$ transporters) in response to direct binding of xenobiotics (e.g., the antifungal ketoconazole) to a discrete ligand-binding domain, allowing the activation domain to interact with the KIX domain of the Gal11p/MED15 subunit of the Mediator coactivator. Mediator in turn interacts with the C-terminal domain (CTD) of the large subunit of RNA polymerase II (Pol II) and facilitates recruitment of Pol II to Pdrlp target genes, allowing transcription. Based on the nuclear receptor paradigm, we speculate that small-molecule inhibitors might be identified that interfere with either productive antifungal binding or with Gal11p/MED15 KIX recruitment by Pdrlp orthologs in pathogenic fungi. Such agents could potentially serve as precursors for therapeutics targeting the molecular basis for antifungalstimulated MDR in the prevalent human pathogen C. glabrata. Reproduced from Thakur et al. (2008a) with permission (originally published in Nature, http:// www.nature.com). 
chemicals distinct from human PXR (Kliewer et al. 2002; Chang and Waxman 2006; Ekins et al. 2008). The utilization of this "low-specificity" ligand response mechanism speaks to the evolutionary economy of using one or only a few sensors/effectors to control a set of "lowspecificity" detoxification genes in response to a plethora of noxious environmental chemicals.

\section{Similarities of fatty-acid-dependent regulation of $\beta$-oxidation and peroxisome proliferation in yeast and mammals}

The PPAR subfamily of nuclear receptors was originally discovered based on their ability to mediate gene activation in response to peroxisome proliferators, a class of hypolipidemic chemicals that derive their name from their stimulatory effects on peroxisomes in rodent livers (Kliewer et al. 2001; Hihi et al. 2002; Desvergne et al. 2006). Later work showed that PPARs could also be activated by direct binding to fatty acids and their metabolites (Bocos et al. 1995; Xu et al. 1999). The PPAR $\alpha$ family member binds to a range of fatty acids, peroxisome proliferators, and nonsteroidal anti-inflammatory drugs (NSAIDs), and activates the expression of fatty acid $\beta$-oxidation and peroxisomal genes as a heterodimer with members of the RXR subfamily of nuclear receptors (Fig. 4; Kliewer et al. 2001; Hihi et al. 2002; Desvergne et al. 2006).

Interestingly, we and others showed recently that the $S$. cerevisiae zinc cluster transcription factor Oaflp together with its heterodimer partner Pip2p activates transcription of fatty acid $\beta$-oxidation and peroxisomal genes in response to direct binding of different fatty acids to the Oaf1p C terminus (Fig. 4; Gurvitz and Rottensteiner 2006; Phelps et al. 2006; Thakur et al. 2008b). Picard and colleagues (Phelps et al. 2006) indeed found sequence and secondary structural similarity of the C-terminal ligand-binding domain of Oaflp and PPARs, suggesting the possibility of an evolutionary relationship between these fatty-acid-regulated transcription factors. However, firm evidence for a structural relationship is lacking and awaits detailed characterization of the ligand-binding domain by X-ray crystallography or NMR.

Similar to the role of PPAR $\alpha$ in peroxisome proliferation in rodent livers, Oaf1p/Pip2p are required for

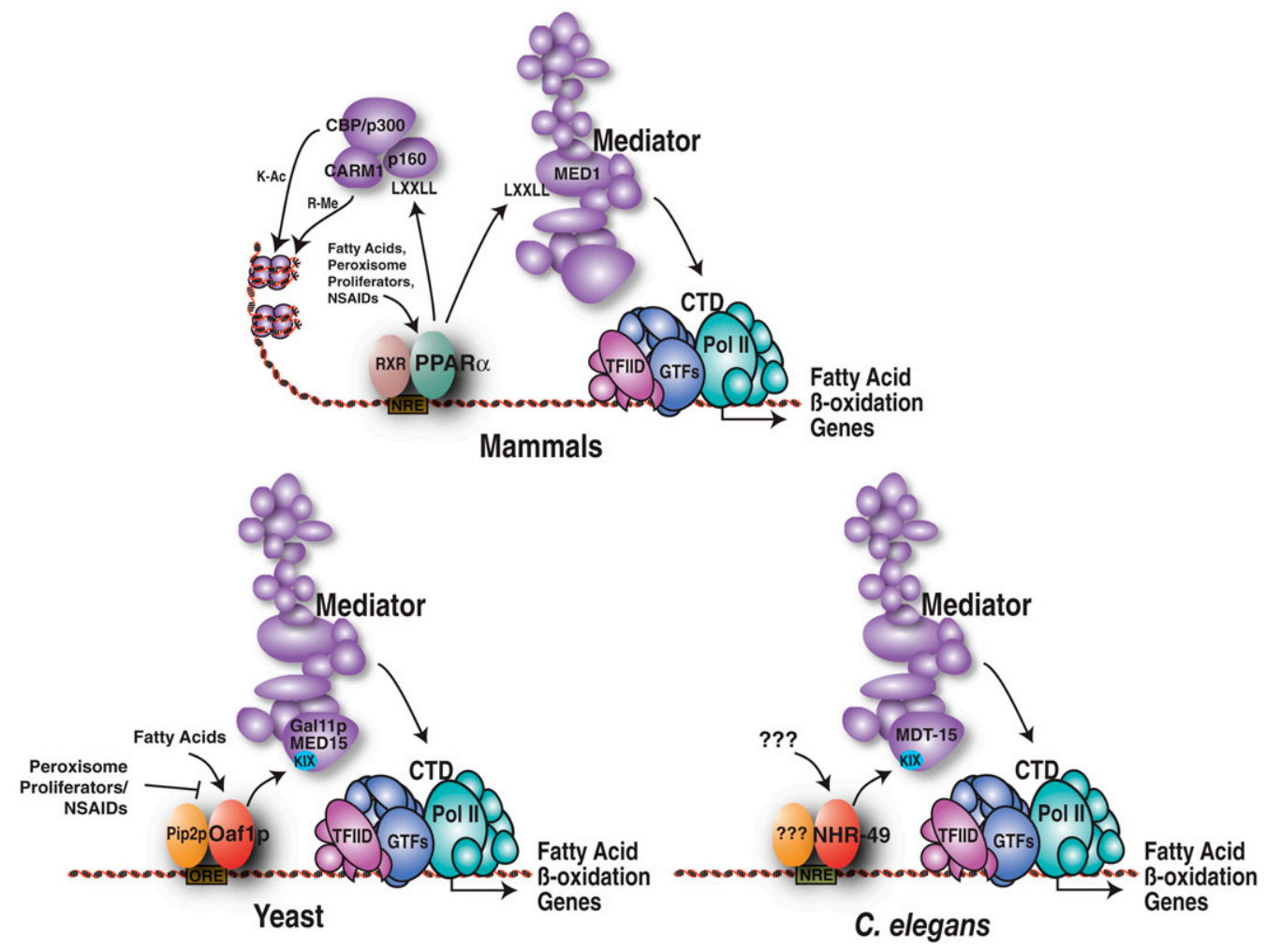

Figure 4. Comparative models of gene activation by mammalian nuclear receptor PPAR $\alpha$, the yeast zinc cluster transcription factors Oaf1p/Pip2p, and the C. elegans nuclear receptor NHR-49. (Bottom) Both Oaf1p and NHR-49 activate genes involved in fatty acid $\beta$ oxidation and lipid homeostasis and have been suggested to represent functional homologs of the vertebrate PPAR $\alpha$ nuclear receptor. (Top) Whereas PPAR $\alpha$ recruits coactivators harboring the LXXLL motif in response to fatty acids, peroxisome proliferators, and NSAIDs, Oaflp and NHR-49 interact with a KIX domain (blue) present in a conserved subunit of the Mediator (Gal11p/MED15 and MDT-15, respectively) and require this subunit for gene activation. Like PPAR $\alpha$, Oaflp binds to fatty acids, peroxisome proliferators, and NSAIDs; however, only fatty acids cause a correct conformational change allowing interaction with Gal11p/MED15 and its KIX domain. Indeed, peroxisome proliferators and NSAIDs act as potent antagonist of fatty-acid-dependent gene activation by Oaflp. NHR49 has thus far not been shown to interact with a cognate ligand(s). Adapted with permission from Thakur et al. (2008b). 
fatty-acid-dependent stimulation of peroxisome proliferation in yeast (Desvergne et al. 2006; Gurvitz and Rottensteiner 2006). Interestingly, Oaflp not only binds directly to different fatty acids, but can also interact with peroxisome proliferators and NSAIDs with high affinity (Thakur et al. 2008b). However, in contrast with PPAR $\alpha$, binding of peroxisome proliferators/NSAIDs to Oaflp does not appear to elicit a productive conformational change allowing proper coactivator engagement. Peroxisome proliferators/NSAIDs are consequently very weak agonists in yeast on their own, and indeed act as strong antagonists of fatty-acid-induced transactivation mediated by Oaflp (Fig. 4; Thakur et al. 2008b).

Oaflp, like Pdrlp orthologs, specifically requires the Gal11p/MED15 Mediator subunit and its KIX domain for fatty-acid-induced gene activation (Thakur et al. 2008b). The findings by Taubert et al. (2006) showing that the PPAR $\alpha$-like nuclear receptor NHR-49 in C. elegans requires the Gal11p/MED15 homolog MDT-15 for transcriptional control of genes involved in fatty acid homeostasis provide further evidence that Oaflp and PPAR $\alpha$ may be evolutionarily related (Fig. 4).

\section{Yeast Hap1p and the Drosophila E75 and human Rev-erb nuclear receptors are heme-regulated transcription factors}

The yeast zinc cluster transcription factor Haplp requires the iron-porphyrin heme for transactivation of target genes involved in oxygen utilization and control of oxidative damage (Zhang and Hach 1999). Indeed, Haplp is thought to represent an important sensor of oxygen tension in yeast. Hap1p represses genes such as $R O X 1, S O D 1$, and $E R G 11$, as well as its own expression, in the absence of heme and under hypoxic conditions (Hon et al. 2005; Hickman and Winston 2007). Increased levels of heme/oxygen results in derepression of Haplp and induced expression of genes required for respiration and for counteracting the deleterious effects of oxidative stress (Zhang and Hach 1999; Hon et al. 2005; Hickman and Winston 2007). Although fulllength Haplp has not been shown to directly interact with heme, Haplp contains seven predicted heme-responsive repeats (HRMs) (consensus sequence: $\mathrm{R} / \mathrm{KCPV} / \mathrm{IDH}$ ) within its negative regulatory domain, and a single HRM peptide derived from Haplp does associate directly with heme (Zhang and Guarente 1995; Hon et al. 2000; Lee et al. 2003). Together, these findings suggest that Haplp might act in a nuclear receptor-like manner to promote hemedependent transactivation.

Until recently, there were no reported metazoan hemeresponsive nuclear receptors; however, a study published in 2005 by Reinking, Krause, and colleagues (Reinking et al. 2005) revealed that the Drosophila nuclear receptor E75 binds directly to heme and functions as a heme- and gas-responsive transcription factor. In their study, heme appears to be acting as a prosthetic group in E75, as it does not easily dissociate, and heme binding results in stabilization of E75. Heme also promotes E75 interaction with its heterodimer partner DHR3. This effect is modulated by the oxidation state of the heme group, indicating a potential role for E75/heme as a redox sensor. Moreover, consistent with a role for $\mathrm{E} 75 / \mathrm{heme}$ as a gas sensor, NO and $\mathrm{CO}$ binding to the heme center inhibits heterodimerization with DHR3. Heme binding to and stabilization of E75 may thus allow transcriptional repression in the absence of gases by interfering with the transactivation potential of its heterodimer partner, DHR3, whereas addition of $\mathrm{NO}$ and $\mathrm{CO}$ disrupts E75 interaction with DHR3, resulting in transcriptional activation of E75/ DHR3 target genes.

The response of E75 to NO and CO rather than oxygen suggests an important functional difference with yeast Haplp. Interestingly, however, a recent study reported that treatment of yeast with reactive NO species (RNS) caused repression of approximately half of the target genes for Haplp, suggesting that RNS treatment may mimic low oxygen conditions (Horan et al. 2006). These genes are mainly involved in respiratory chain function, fatty acid and sterol synthesis, as well as iron homeostasis. Moreover, NO is produced by yeast mitochondria under hypoxic conditions, resulting in the activation of the CYC7 gene, a known Haplp target that is also activated potently by heme (Prezant et al. 1987; Castello et al. 2006). These findings suggest that Haplp may not only respond to oxygen tension, but might also potentially be regulated by NO.

Like Drosophila E75, the human E75 homologs Rev$\operatorname{erb} \alpha$ and Rev-erb $\beta$ lack the C-terminal AF2 activation domain and act as transcriptional repressors by recruiting the N-CoR/HDAC3 corepressor complex (Downes et al. 1996; Zamir et al. 1996; Renaud et al. 2000; Ishizuka and Lazar 2003). In mammals, the Rev-erb proteins are important regulators of circadian rhythm in a complex interplay with another nuclear receptor subfamily, ROR, the nuclear receptor coactivator PGC- $1 \alpha$, as well as other transcription factors, including NPAS2/BMAL1 and PER proteins (Grimaldi and Sassone-Corsi 2007). Rev-erb proteins were not thought to have ligands; however, two recent studies (Raghuram et al. 2007; Yin et al. 2007) showed that Rev-erb $\alpha$ and $\beta$ also interact with heme. Unlike E75 (but similar to Haplp), Rev-erb binding to heme appears to be reversible, with a $\mathrm{Kd}$ of $2-4 \mu \mathrm{M}$. This indicates that heme acts as a true ligand for Rev-erb nuclear receptors rather than as a prosthetic group, as suggested for E75. In contrast with the action of heme as an activator of yeast Haplp, binding of heme to Rev-erb promotes its function as a transcriptional repressor and enhances association of Rev-erb with the N-CoR/HDAC3 corepressor complex (Raghuram et al. 2007; Yin et al. 2007). It is presently unclear whether Rev-erb/heme functions as a gas sensor like Haplp and E75. As circadian rhythm is linked to heme synthesis, oxygen regulation, and lipid and sterol homeostasis, Rev-erb/heme may also modulate processes conserved with Haplp in yeast (Ramakrishnan and Muscat 2006; Grimaldi and SassoneCorsi 2007; Burris 2008).

Together, these findings highlight intriguing functional similarities of a heme/gas-responsive yeast zinc cluster transcription factor and metazoan heme-regulated nuclear receptors. 
Other small molecule-regulated zinc cluster transcription factors in S. cerevisiae

In this section, we briefly highlight additional small molecule-regulated zinc cluster transcription factors in yeast that do not appear to exhibit direct analogy or functional similarity to specific metazoan nuclear receptors (Table 1). It is possible, however, that further studies of orphan metazoan nuclear receptors may uncover additional analogies to some of these yeast zinc cluster transcription factors.

Several yeast zinc cluster transcription factors are regulated by sugars. Gal4p, the most studied member of the zinc cluster transcription factor family, regulates expression of genes involved in galactose catabolism in response to galactose (Reece et al. 2006; Traven et al. 2006). Mal63p is a maltose-inducible activator of genes in the maltose catabolism pathway (Hu et al. 1999; Danzi et al. 2000; Danzi et al. 2003), and the Rgtlp zinc cluster family member mediates glucose-induced transcription of hexose transporter genes (Ozcan et al. 1996).

A number of yeast zinc cluster transcription factors control genes involved in amino acid biosynthesis or catabolism in response to changes in amino acid availability or biosynthesis intermediates. For example, Leu3p, a regulator of genes in the branched-chain amino acid biosynthetic pathways and nitrogen assimilation, activates transcription in response to the leucine biosynthesis intermediate $\alpha$-IPM (Kohlhaw 2003). Put3p, a master regulator of the proline-utilization pathway, mediates transactivation in response to direct binding to proline (Brandriss 1987; Marczak and Brandriss 1989; Axelrod et al. 1991; Sellick and Reece 2003), while Lys14p is an activator of genes encoding enzymes in the lysine biosynthesis pathway that responds to the lysine biosynthesis intermediate $\alpha$-aminoadipate semialdehyde (Feller et al. 1994; El Alami et al. 2002). The ArgRIIp/Arg81p family members function in DNA-binding complex with MADS-box transcription factors ArgIp and Mcmlp to regulate transcription of arginine catabolic and anabolic genes in response to arginine (Amar et al. 2000), Aro80p controls genes involved in aromatic amino acid catabolism in response to aromatic amino acids (Iraqui et al. 1999), and the Cha4p zinc cluster transcription factor activates transcription of genes required for the catabolism of serine and threonine in response to elevated levels of these amino acids and in the absence of other nitrogen sources (Holmberg and Schjerling 1996).

Other examples of small molecule-regulated zinc cluster transcription factors include Warlp, which activates the $A B C$ transporter Pdr12p to promote weak organic acid efflux in response to high concentrations of weak organic acids, such as sorbate, benzoate, and propionate (Hatzixanthis et al. 2003; Kren et al. 2003; Gregori et al. 2008), Upc2p and Ecm22p, paralogous members of the yeast zinc cluster transcription factor family that regulate ergosterol biosynthesis genes (ERGs) in response to sterol depletion (Smith et al. 1996; Vik and Rine 2001), and Pprlp, which stimulates transcription of URA genes in response to the pyrimidine biosynthesis intermediates dihydroorotic acid and orotic acid (Flynn and Reece 1999).

Together, these examples indicate that fungi harbor a large family of small molecule-regulated transcription factors that rivals metazoan nuclear receptors in diversity of ligand-responsive gene regulatory pathways governing biologically important functions such as metabolism and response to environmental cues.

\section{Concluding remarks}

Evolutionary convergence or divergence of eukaryotic ligand-dependent transcription factors?

Because of the lack of overt sequence and structural similarities of fungal zinc cluster transcription factors and metazoan nuclear receptors, it is possible that the architectural and functional similarities and analogies discussed here are the product of environmental constraints that

Table 1. List of yeast zinc cluster transcription factors with cognate small-molecule regulators, and potential metazoan nuclear receptor analogs

\begin{tabular}{lllc}
\hline $\begin{array}{l}\text { Fungal zinc cluster } \\
\text { transcription factor }\end{array}$ & \multicolumn{1}{c}{ Pathway/s) regulated } & $\begin{array}{c}\text { Regulating small } \\
\text { molecule(s) }\end{array}$ & Metazoan analog(s) \\
\hline $\begin{array}{l}\text { Pdr1p/Pdr3p } \\
\text { Oaf1p/Pip2p }\end{array}$ & Multidrug resistance & Xenobiotics & PXR \\
Hap1p & Fatty acid $\beta$-oxidation & Fatty acids & PPAR $/$ NHR-49 \\
Gal4p & Oxidative stress response & Heme & - \\
Mal63p & Galactose catabolism & Galactose & - \\
Rgt1p & Maltose catabolism & Maltose & - \\
Leu3p & Glucose uptake & Glucose & - \\
& Branched chain amino acid synthesis & $\alpha$-IPM & - \\
Put3p & and ammonia assimilation & & - \\
Pprlp & Proline catabolism & Proline & - \\
Upc2p/Ecm22p & Pyrimidine synthesis & DHO/OA & PXR? \\
Warlp & Ergosterol synthesis & Ergosterols (-) & - \\
Lys14p & Weak organic acid resistance & Weak organic acids & - \\
ArgRIIp/Arg81p & Lysine synthesis & $\alpha$-AASA & - \\
Cha4p & Arginine catabolism & Arginine & - \\
Aro80p & Ser/Thr catabolism & Ser/Thr & \\
\hline
\end{tabular}


might have favored convergence of evolutionarily unrelated protein families onto a common mechanistic strategy as the most efficient solution to gene regulation in response to environmental or endogenous small molecules. However, the biological importance of rapid and accurate sensing of nutrients, toxins, and other chemical signals suggests that there would have been strong selective pressure during early eukaryotic evolution to elaborate and maintain sensor and effector mechanisms that provide survival advantages in the face of environmental challenges. Intense interspecies competition may also have promoted extensive diversification and specialization of such sensors and effectors, allowing unique species adaptation to specific environmental niches. Such diversification could obscure and impede evolutionary studies that rely solely on primary DNA and/or protein sequence conservation, and may necessitate the addition of complementary approaches, including investigation of structural and functional analogy of sensor/effector protein families. Further detailed functional and structural studies of zinc cluster transcription factors and orphan metazoan nuclear receptors should shed light on whether these small molecule-regulated transcription factor families arose from convergence mechanisms or whether they may actually share a common evolutionary origin.

\section{Insights into metazoan nuclear receptor functions by} studying fungal zinc cluster transcription factors?

Studies of yeast have yielded troves of useful information regarding fundamental biological pathways conserved in eukaryotes. The examples of functional similarities of fungal zinc cluster transcription factors and metazoan nuclear receptors discussed above should provide the impetus to investigate whether additional mechanistic analogies exist that might guide our understanding of nuclear receptor signaling pathways and metazoan biology that could have important biomedical relevance. For example, could certain orphan metazoan nuclear receptors regulate metabolic pathways, such as amino acid or pyrimidine biosynthesis and/or catabolism, in response to pathway components, akin to Put3p/proline and Pprlp/orotic acid? Also, given the well-established role of mutations of Pdrlp orthologs and analogs (e.g., Taclp in Candida albicans) in causing constitutive upregulation of MDR in fungi, a potential analogous role for PXR mutation/upregulation in MDR in human cancers should be fully explored. Indeed, overexpression of the PXR target gene P-glycoprotein/MDR1 is a significant cause of MDR in tumors (Breier et al. 2005; Gottesman and Ling 2006). Although in vitro studies have revealed that mutations in the PXR ligand-binding domain can indeed result in constitutive activity (Watkins et al. 2001), and a few cell culture studies have documented a correlation of PXR level and activity with CYP3A4 and/or MDR1 expression and MDR in cancer cells (Chen et al. 2007; Mensah-Osman et al. 2007; Gupta et al. 2008), there is a relative paucity of research into the potential role of PXR in MDR in human cancers in vivo.
As discussed in detail above, studies by others and us revealed a key role for the Mediator subunit Gall1p/ MED15 and its activator-targeted KIX domain in gene activation by certain fungal zinc cluster transcription factors and metazoan nuclear receptors. It will be interesting to investigate whether nuclear receptors in higher organisms such as mammals might also utilize MED15 orthologs as their regulatory conduit.

\section{Therapeutic implications of the identification of nuclear receptor-like transcription factors in fungal pathogens}

Insights into the molecular mechanism of transactivation by mammalian nuclear receptors, such as coactivator/ corepressor requirements, have aided the identification of both natural ligands and exogenous agonists/antagonists that have clinical utility. Our findings revealing that Pdrlp orthologs function as direct sensors of xenobiotics in a manner analogous to the mammalian PXR nuclear receptor provide the mechanistic rationale to identify novel antiMDR compounds that might be useful to therapeutically target multidrug-resistant pathogenic fungal infections.

Fungal pathogens have emerged as clinically important infectious agents in immunocompromised individuals, including those afflicted by AIDS, cancer patients treated with chemotherapy, transplant recipients on anti-rejection drugs, and advanced diabetes patients (Fidel et al. 1999; Klepser 2001, 2006; Kaur et al. 2005; Aperis et al. 2006). Similar to $S$. cerevisiae Pdrlp, the C. glabrata Pdrlp ortholog can also directly bind to the antifungal ketoconazole and requires a Gal11p/MED15 ortholog (CgGa$111 \mathrm{Ap}$ ) for xenobiotic-dependent activation of drug efflux pump genes and promotion of antifungal resistance (Thakur et al. 2008a). Moreover, deletion of either CgPdrlp or CgGal11Ap resensitizes C. glabrata to standard antifungals and leads to increased animal survival in a $C$. elegans fungal pathogenicity model in the presence of the antifungal fluconazole (Thakur et al. 2008a), suggesting that this nuclear receptor-like transcription factor and its cognate coactivator might serve as a promising therapeutic target to combat the intrinsic MDR often encountered when treating C. glabrata infections in the clinic.

In C. albicans, the Taclp and Mrrlp zinc cluster transcription factors activate $C a C D R 1 / C a C D R 2$ and $C a M D R 1$, respectively, and mediate responses to xenobiotics, such as azoles and rifampicin (Coste et al. 2004; Morschhauser et al. 2007). The mechanism by which antifungals and other xenobiotics activate transcription of drug efflux pumps in C. albicans has not been determined; however, based on our findings in $S$. cerevisiae and C. glabrata (Thakur et al. 2008b), we speculate that these zinc cluster transcription factors might also serve as direct sensors/effectors of xenobiotics, and may thus represent novel targets for therapeutic intervention to reverse MDR in this prevalent human pathogen.

The nuclear receptor paradigm could guide therapeutic strategies to control MDR in Candida species. For example, one might be able to identify antagonists that directly 
compete with xenobiotics for interaction with the xenobioticbinding domain without causing a conformational change allowing transactivation (Fig. 3). Such "cotherapeutics" could augment standard antifungal therapies by directly targeting the mechanistic underpinnings of inducible MDR. The precedence for this approach is the identification of tamoxifen and bicalutamide as potent antagonists for the estrogen and androgen receptors, respectively (Culig et al. 2003; Lewis-Wambi and Jordan 2005).

A second potential approach to identify novel antiMDR therapeutics relies on the discovery of the KIX domain in Gal11p/MED15 orthologs as targets of the activation domains of Pdrlp orthologs/analogs in pathogenic fungi (Fig. 3; Thakur et al. 2008a). It might be possible to screen for small-molecule inhibitors of the activator/coactivator interaction; indeed, our preliminary results from a screen for inhibitors of the C. glabrata Pdrlp activation domain with the CgGall1Ap KIX domain suggest the feasibility of this strategy (H. Arthanari, G. Wagner, and A.M. Näär, unpubl.).

The azole class of antifungals target the ergosterol synthesis pathway by inhibition of Erg11p (lanosterol $14 \alpha$-demethylase), encoded by a key Upc2p/Ecm $22 p-$ regulated gene. Consistent with this notion, azole treatment (and, presumably, ensuing ergosterol depletion) of yeast results in striking up-regulation of Upc2p/Ecm22pdependent expression of ergosterol biosynthesis genes (Vik and Rine 2001). This suggests that Upc2p/Ecm22p orthologs in pathogenic fungi might play important roles in azole resistance. Indeed, C. albicans harbors a single $\mathrm{Upc} 2 \mathrm{p} / \mathrm{Ecm} 22 \mathrm{p}$ ortholog (CaUpc2p) that has been implicated in azole resistance (Oliver et al. 2007; Dunkel et al. 2008; Hoot et al. 2008; Znaidi et al. 2008). If CaUpc2p by analogy with other zinc cluster transcription factors also interacts with cognate ligands, it might be possible to identify high-affinity small-molecule antagonists that lock $\mathrm{CaUpc} 2 \mathrm{p}$ in an inactive conformation, and which could serve as cotherapeutics to enhance the efficacy of standard azole therapy.

Many members of the zinc cluster transcription factor family exhibit mechanistic similarities (i.e., liganddependent transactivation) with nuclear receptors, but also have distinct ligand requirements and gene regulatory pathways (e.g., $\alpha$-IPM for Leu3p regulation of leucine biosynthesis in $S$. cerevisiae) as compared with metazoan nuclear receptors. This difference in ligand specificity could potentially be exploited by identifying unique ligand-dependent gene regulatory pathways in pathogenic fungi that are essential for their proliferation, viability, or induction of pathogenic programs (e.g., var genes) (De Las Penas et al. 2003; Castano et al. 2005; Domergue et al. 2005), and which could represent promising therapeutic targets for small-molecule antagonists, perhaps without interfering with metazoan nuclear receptor pathways due to the lack of functional similarity.

\section{References}

Alenquer, M., Tenreiro, S., and Sa-Correia, I. 2006. Adaptive response to the antimalarial drug artesunate in yeast involves Pdr1p/Pdr3p-mediated transcriptional activation of the resistance determinants TPO1 and PDR5. FEMS Yeast Res. 6: 1130-1139.

Amar, N., Messenguy, F., El Bakkoury, M., and Dubois, E. 2000. ArgRII, a component of the ArgR-Mcm l complex involved in the control of arginine metabolism in Saccharomyces cerevisiae, is the sensor of arginine. Mol. Cell. Biol. 20: 20872097.

Aperis, G., Myriounis, N., Spanakis, E.K., and Mylonakis, E. 2006. Developments in the treatment of candidiasis: More choices and new challenges. Expert Opin. Investig. Drugs. 15: 1319-1336.

Axelrod, J.D., Majors, J., and Brandriss, M.C. 1991. Prolineindependent binding of PUT3 transcriptional activator protein detected by footprinting in vivo. Mol. Cell. Biol. 11: 564567.

Bai, J., Uehara, Y., and Montell, D.J. 2000. Regulation of invasive cell behavior by taiman, a Drosophila protein related to AIB1, a steroid receptor coactivator amplified in breast cancer. Cell 103: 1047-1058.

Balzi, E. and Goffeau, A. 1995. Yeast multidrug resistance: The PDR network. I. Bioenerg. Biomembr. 27: 71-76.

Balzi, E., Chen, W., Ulaszewski, S., Capieaux, E., and Goffeau, A. 1987. The multidrug resistance gene PDR1 from Saccharomyces cerevisiae. J. Biol. Chem. 262: 16871-16879.

Bertrand, S., Brunet, F.G., Escriva, H., Parmentier, G., Laudet, V., and Robinson-Rechavi, M. 2004. Evolutionary genomics of nuclear receptors: From twenty-five ancestral genes to derived endocrine systems. Mol. Biol. Evol. 21: 1923-1937.

Bevan, C.L., Hoare, S., Claessens, F., Heery, D.M., and Parker, M.G. 1999. The AF1 and AF2 domains of the androgen receptor interact with distinct regions of SRC1. Mol. Cell. Biol. 19: 8383-8392.

Bocos, C., Gottlicher, M., Gearing, K., Banner, C., Enmark, E., Teboul, M., Crickmore, A., and Gustafsson, J.A. 1995. Fatty acid activation of peroxisome proliferator-activated receptor (PPAR). J. Steroid Biochem. Mol. Biol. 53: 467-473.

Brandriss, M.C. 1987. Evidence for positive regulation of the proline utilization pathway in Saccharomyces cerevisiae. Genetics 117: 429-435.

Breier, A., Barancik, M., Sulova, Z., and Uhrik, B. 2005. P-glycoprotein-Implications of metabolism of neoplastic cells and cancer therapy. Curr. Cancer Drug Targets 5: 457-468.

Burris, T.P. 2008. Nuclear hormone receptors for heme: REV$E R B \alpha$ and REV-ERB $\beta$ are ligand-regulated components of the mammalian clock. Mol. Endocrinol. 22: 1509-1520.

Carvajal, E., van den Hazel, H.B., Cybularz-Kolaczkowska, A., Balzi, E., and Goffeau, A. 1997. Molecular and phenotypic characterization of yeast PDR1 mutants that show hyperactive transcription of various $\mathrm{ABC}$ multidrug transporter genes. Mol. Gen. Genet. 256: 406-415.

Castano, I., Pan, S.J., Zupancic, M., Hennequin, C., Dujon, B., and Cormack, B.P. 2005. Telomere length control and transcriptional regulation of subtelomeric adhesins in Candida glabrata. Mol. Microbiol. 55: 1246-1258.

Castello, P.R., David, P.S., McClure, T., Crook, Z., and Poyton, R.O. 2006. Mitochondrial cytochrome oxidase produces nitric oxide under hypoxic conditions: Implications for oxygen sensing and hypoxic signaling in eukaryotes. Cell Metab. 3: 277-287.

Chang, T.K. and Waxman, D.J. 2006. Synthetic drugs and natural products as modulators of constitutive androstane receptor (CAR) and pregnane X receptor (PXR). Drug Metab. Rev. 38: $51-73$.

Chen, Y., Tang, Y., Wang, M.T., Zeng, S., and Nie, D. 2007. Human pregnane $X$ receptor and resistance to chemotherapy in prostate cancer. Cancer Res. 67: 10361-10367. 
Coste, A.T., Karababa, M., Ischer, F., Bille, J., and Sanglard, D. 2004. TAC1, transcriptional activator of CDR genes, is a new transcription factor involved in the regulation of Candida albicans ABC transporters CDR1 and CDR2. Eukaryot. Cell. 3: $1639-1652$.

Culig, Z., Klocker, H., Bartsch, G., Steiner, H., and Hobisch, A. 2003. Androgen receptors in prostate cancer. J. Urol. 170: 1363-1369.

Danzi, S.E., Zhang, B., and Michels, C.A. 2000. Alterations in the Saccharomyces MAL-activator cause constitutivity but can be suppressed by intragenic mutations. Curr. Genet. 38: 233-240.

Danzi, S.E., Bali, M., and Michels, C.A. 2003. Clustered-charge to alanine scanning mutagenesis of the Mal63 MAL-activator C-terminal regulatory domain. Curr. Genet. 44: 173-183.

Deeley, R.G., Westlake, C., and Cole, S.P. 2006. Transmembrane transport of endo- and xenobiotics by mammalian ATPbinding cassette multidrug resistance proteins. Physiol. Rev. 86: 849-899.

De Las Penas, A., Pan, S.J., Castano, I., Alder, J., Cregg, R., and Cormack, B.P. 2003. Virulence-related surface glycoproteins in the yeast pathogen Candida glabrata are encoded in subtelomeric clusters and subject to RAP1- and SIR-dependent transcriptional silencing. Genes \& Dev. 17: 2245-2258.

Delaveau, T., Delahodde, A., Carvajal, E., Subik, J., and Jacq, C. 1994. PDR3, a new yeast regulatory gene, is homologous to PDR1 and controls the multidrug resistance phenomenon. Mol. Gen. Genet. 244: 501-511.

Desvergne, B. and Wahli, W. 1999. Peroxisome proliferatoractivated receptors: Nuclear control of metabolism. Endocr. Rev. 20: 649-688.

Desvergne, B., Michalik, L., and Wahli, W. 2006. Transcriptional regulation of metabolism. Physiol. Rev. 86: 465-514.

Domergue, R., Castano, I., De Las Penas, A., Zupancic, M., Lockatell, V., Hebel, J.R., Johnson, D., and Cormack, B.P. 2005. Nicotinic acid limitation regulates silencing of Candida adhesins during UTI. Science 308: 866-870.

Downes, M., Burke, L.J., Bailey, P.J., and Muscat, G.E. 1996. Two receptor interaction domains in the corepressor, N-CoR/ RIP13, are required for an efficient interaction with Rev-erbA $\alpha$ and RVR: Physical association is dependent on the E region of the orphan receptors. Nucleic Acids Res. 24: 4379-4386.

Dunkel, N., Liu, T.T., Barker, K.S., Homayouni, R., Morschhauser, J., and Rogers, P.D. 2008. A gain-of-function mutation in the transcription factor Upc2p causes upregulation of ergosterol biosynthesis genes and increased fluconazole resistance in a clinical Candida albicans isolate. Eukaryot. Cell 7: 11801190.

Ekins, S., Reschly, E.J., Hagey, L.R., and Krasowski, M.D. 2008. Evolution of pharmacologic specificity in the pregnane $\mathrm{X}$ receptor. BMC Evol. Biol. 8: 103. doi: 10.1186/1471-2148-8103.

El Alami, M., Feller, A., Pierard, A., and Dubois, E. 2002. The proper folding of a long C-terminal segment of the yeast Lys14p regulator is required for activation of LYS genes in response to the metabolic effector. Mol. Microbiol. 43: 1629-1639.

Escriva, H., Delaunay, F., and Laudet, V. 2000. Ligand binding and nuclear receptor evolution. Bioessays 22: 717-727.

Escriva, H., Bertrand, S., and Laudet, V. 2004. The evolution of the nuclear receptor superfamily. Essays Biochem. 40: 11-26.

Feller, A., Dubois, E., Ramos, F., and Pierard, A. 1994. Repression of the genes for lysine biosynthesis in Saccharomyces cerevisiae is caused by limitation of Lys14-dependent transcriptional activation. Mol. Cell. Biol. 14: 6411-6418.

Fidel Jr., P.L., Vazquez, J.A., and Sobel, J.D. 1999. Candida glabrata: Review of epidemiology, pathogenesis, and clinical disease with comparison to C. albicans. Clin. Microbiol. Rev. 12: 80-96.

Flynn, P.J. and Reece, R.J. 1999. Activation of transcription by metabolic intermediates of the pyrimidine biosynthetic pathway. Mol. Cell. Biol. 19: 882-888.

Freedman, L.P. and Luisi, B.F. 1993. On the mechanism of DNA binding by nuclear hormone receptors: A structural and functional perspective. J. Cell. Biochem. 51: 140-150.

Friden, P., Reynolds, C., and Schimmel, P. 1989. A large internal deletion converts yeast LEU3 to a constitutive transcriptional activator. Mol. Cell. Biol. 9: 4056-4060.

Gampe Jr., R.T., Montana, V.G., Lambert, M.H., Miller, A.B., Bledsoe, R.K., Milburn, M.V., Kliewer, S.A., Willson, T.M., and $\mathrm{Xu}, \mathrm{H} . \mathrm{E} .2000$. Asymmetry in the PPAR $\gamma / \mathrm{RXR} \alpha$ crystal structure reveals the molecular basis of heterodimerization among nuclear receptors. Mol. Cell 5: 545-555.

Gao, C., Wang, L., Milgrom, E., and Shen, W.C. 2004. On the mechanism of constitutive Pdr1 activator-mediated PDR5 transcription in Saccharomyces cerevisiae: Evidence for enhanced recruitment of coactivators and altered nucleosome structures. J. Biol. Chem. 279: 42677-42686.

Glass, C.K. and Rosenfeld, M.G. 2000. The coregulator exchange in transcriptional functions of nuclear receptors. Genes \& Dev. 14: 121-141.

Goffeau, A. 2008. Drug resistance: The fight against fungi. Nature 452: 541-542.

Gottesman, M.M. and Ling, V. 2006. The molecular basis of multidrug resistance in cancer: The early years of P-glycoprotein research. FEBS Lett. 580: 998-1009.

Gregori, C., Schüller, C., Frohner, I.E., Ammerer, G., and Kuchler, K. 2008. Weak organic acids trigger conformational changes of the yeast transcription factor Warl in vivo to elicit stress adaptation. J. Biol. Chem. 283: 25752-25764.

Grimaldi, B. and Sassone-Corsi, P. 2007. Circadian rhythms: Metabolic clockwork. Nature 447: 386-387.

Gupta, D., Venkatesh, M., Wang, H., Kim, S., Sinz, M., Goldberg, G.L., Whitney, K., Longley, C., and Mani, S. 2008. Expanding the roles for pregnane $\mathrm{X}$ receptor in cancer: Proliferation and drug resistance in ovarian cancer. Clin. Cancer Res. 14: $5332-5340$

Gurvitz, A. and Rottensteiner, H. 2006. The biochemistry of oleate induction: Transcriptional upregulation and peroxisome proliferation. Biochim. Biophys. Acta 1763: 1392-1402.

Handschin, C. and Meyer, U.A. 2005. Regulatory network of lipid-sensing nuclear receptors: Roles for CAR, PXR, LXR, and FXR. Arch. Biochem. Biophys. 433: 387-396.

Hatzixanthis, K., Mollapour, M., Seymour, I., Bauer, B.E., Krapf, G., Schuller, C., Kuchler, K., and Piper, P.W. 2003. Moderately lipophilic carboxylate compounds are the selective inducers of the Saccharomyces cerevisiae Pdr12p ATP-binding cassette transporter. Yeast 20: 575-585.

Hellauer, K., Rochon, M.H., and Turcotte, B. 1996. A novel DNA binding motif for yeast zinc cluster proteins: The Leu3p and Pdr3p transcriptional activators recognize everted repeats. Mol. Cell. Biol. 16: 6096-6102.

Hickman, M.J. and Winston, F. 2007. Heme levels switch the function of Hap1 of Saccharomyces cerevisiae between transcriptional activator and transcriptional repressor. Mol. Cell. Biol. 27: 7414-7424.

Hihi, A.K., Michalik, L., and Wahli, W. 2002. PPARs: Transcriptional effectors of fatty acids and their derivatives. Cell. Mol. Life Sci. 59: 790-798.

Holmberg, S. and Schjerling, P. 1996. Cha4p of Saccharomyces cerevisiae activates transcription via serine/threonine response elements. Genetics 144: 467-478. 
Hon, T., Hach, A., Lee, H.C., Cheng, T., and Zhang, L. 2000 Functional analysis of heme regulatory elements of the transcriptional activator Hap1. Biochem. Biophys. Res. Commun. 273: 584-591.

Hon, T., Lee, H.C., Hu, Z., Iyer, V.R., and Zhang, L. 2005. The heme activator protein Hap1 represses transcription by a heme-independent mechanism in Saccharomyces cerevisiae. Genetics 169: 1343-1352.

Hoot, S.J., Oliver, B.G., and White, T.C. 2008. Candida albicans UPC2 is transcriptionally induced in response to antifungal drugs and anaerobicity through Upc2p-dependent and -independent mechanisms. Microbiology 154: 2748-2756.

Horan, S., Bourges, I., and Meunier, B. 2006. Transcriptional response to nitrosative stress in Saccharomyces cerevisiae. Yeast 23: 519-535.

Hu, Z., Gibson, A.W., Kim, J.H., Wojciechowicz, L.A., Zhang, B., and Michels, C.A. 1999. Functional domain analysis of the Saccharomyces MAL-activator. Curr. Genet. 36: 1-12.

Iraqui, I., Vissers, S., Andre, B., and Urrestarazu, A. 1999. Transcriptional induction by aromatic amino acids in Saccharomyces cerevisiae. Mol. Cell. Biol. 19: 3360-3371.

Ishizuka, T. and Lazar, M.A. 2003. The N-CoR/histone deacetylase 3 complex is required for repression by thyroid hormone receptor. Mol. Cell. Biol. 23: 5122-5131.

Jeong, C.J., Yang, S.H., Xie, Y., Zhang, L., Johnston, S.A., and Kodadek, T. 2001. Evidence that Gall1 protein is a target of the Gal4 activation domain in the mediator. Biochemistry 40: 9421-9427.

Katzmann, D.J., Burnett, P.E., Golin, J., Mahe, Y., and MoyeRowley, W.S. 1994. Transcriptional control of the yeast PDR5 gene by the PDR3 gene product. Mol. Cell. Biol. 14: 4653-4661.

Kaur, R., Domergue, R., Zupancic, M.L., and Cormack, B.P. 2005. A yeast by any other name: Candida glabrata and its interaction with the host. Curr. Opin. Microbiol. 8: 378-384.

Klepser, M.E. 2001. Antifungal resistance among Candida species. Pharmacotherapy 21: 124S-132S.

Klepser, M.E. 2006. Candida resistance and its clinical relevance. Pharmacotherapy 26: 68S-75S.

Kliewer, S.A., Xu, H.E., Lambert, M.H., and Willson, T.M. 2001. Peroxisome proliferator-activated receptors: From genes to physiology. Recent Prog. Horm. Res. 56: 239-263.

Kliewer, S.A., Goodwin, B., and Willson, T.M. 2002. The nuclear pregnane X receptor: A key regulator of xenobiotic metabolism. Endocr. Rev. 23: 687-702.

Kohlhaw, G.B. 2003. Leucine biosynthesis in fungi: Entering metabolism through the back door. Microbiol. Mol. Biol. Rev. 67: 1-15.

Kren, A., Mamnun, Y.M., Bauer, B.E., Schuller, C., Wolfger, H., Hatzixanthis, K., Mollapour, M., Gregori, C., Piper, P., and Kuchler, K. 2003. Warlp, a novel transcription factor controlling weak acid stress response in yeast. Mol. Cell. Biol. 23: $1775-1785$.

Krishna, S.S., Majumdar, I., and Grishin, N.V. 2003. Structural classification of zinc fingers: Survey and summary. Nucleic Acids Res. 31: 532-550.

Kumar, R., Lee, J.C., Bolen, D.W., and Thompson, E.B. 2001. The conformation of the glucocorticoid receptor af1/taul domain induced by osmolyte binds co-regulatory proteins. J. Biol. Chem. 276: 18146-18152.

Kurokawa, R., Yu, V.C., Näär, A., Kyakumoto, S., Han, Z., Silverman, S., Rosenfeld, M.G., and Glass, C.K. 1993. Differential orientations of the DNA-binding domain and carboxyterminal dimerization interface regulate binding site selection by nuclear receptor heterodimers. Genes \& Dev. 7: 1423-1435.
Lee, H.C., Hon, T., Lan, C., and Zhang, L. 2003. Structural environment dictates the biological significance of hemeresponsive motifs and the role of Hsp90 in the activation of the heme activator protein Hap1. Mol. Cell. Biol. 23:5857-5866.

Lewis-Wambi, J.S. and Jordan, V.C. 2005. Treatment of postmenopausal breast cancer with Selective Estrogen Receptor Modulators (SERMs). Breast Dis. 24: 93-105.

Lucau-Danila, A., Lelandais, G., Kozovska, Z., Tanty, V., Delaveau, T., Devaux, F., and Jacq, C. 2005. Early expression of yeast genes affected by chemical stress. Mol. Cell. Biol. 25: 18601868.

Luisi, B.F., Schwabe, J.W., and Freedman, L.P. 1994. The steroid/ nuclear receptors: From three-dimensional structure to complex function. Vitam. Horm. 49: 1-47.

MacPherson, S., Larochelle, M., and Turcotte, B. 2006. A fungal family of transcriptional regulators: The zinc cluster proteins. Microbiol. Mol. Biol. Rev. 70: 583-604.

Maglich, J.M., Sluder, A., Guan, X., Shi, Y., McKee, D.D., Carrick, K., Kamdar, K., Willson, T.M., and Moore, J.T. 2001. Comparison of complete nuclear receptor sets from the human, Caenorhabditis elegans and Drosophila genomes. Genome Biol. 2: RESEARCH0029. doi: 10.1186/ gb-2001-2-8-research0029.

Malik, S. and Roeder, R.G. 2005. Dynamic regulation of pol II transcription by the mammalian Mediator complex. Trends Biochem. Sci. 30: 256-263.

Mamane, Y., Hellauer, K., Rochon, M.H., and Turcotte, B. 1998. A linker region of the yeast zinc cluster protein leu $3 p$ specifies binding to everted repeat DNA. I. Biol. Chem. 273: $18556-18561$.

Mamnun, Y.M., Schuller, C., and Kuchler, K. 2004. Expression regulation of the yeast PDR5 ATP-binding cassette (ABC) transporter suggests a role in cellular detoxification during the exponential growth phase. FEBS Lett. 559: 111-117.

Mangelsdorf, D.J., Thummel, C., Beato, M., Herrlich, P., Schutz, G., Umesono, K., Blumberg, B., Kastner, P., Mark, M., Chambon, P., et al. 1995. The nuclear receptor superfamily: The second decade. Cell 83: 835-839.

Marczak, J.E. and Brandriss, M.C. 1989. Isolation of constitutive mutations affecting the proline utilization pathway in Saccharomyces cerevisiae and molecular analysis of the PUT3 transcriptional activator. Mol. Cell. Biol. 9: 4696-4705.

Mensah-Osman, E.J., Thomas, D.G., Tabb, M.M., Larios, J.M., Hughes, D.P., Giordano, T.J., Lizyness, M.L., Rae, J.M., Blumberg, B., Hollenberg, P.F., et al. 2007. Expression levels and activation of a PXR variant are directly related to drug resistance in osteosarcoma cell lines. Cancer 109: 957-965.

Mitro, N., Mak, P.A., Vargas, L., Godio, C., Hampton, E., Molteni, V., Kreusch, A., and Saez, E. 2007. The nuclear receptor LXR is a glucose sensor. Nature 445: 219-223.

Moras, D. and Gronemeyer, H. 1998. The nuclear receptor ligand-binding domain: Structure and function. Curr. Opin. Cell Biol. 10: 384-391.

Morschhauser, J., Barker, K.S., Liu, T.T., Bla, B.W.J., Homayouni, R., and Rogers, P.D. 2007. The transcription factor Mrrlp controls expression of the MDR1 efflux pump and mediates multidrug resistance in Candida albicans. PLoS Pathog. 3: e164. doi: 10.1371/journal.ppat.0030164.

Moye-Rowley, W.S. 2003. Transcriptional control of multidrug resistance in the yeast Saccharomyces. Prog. Nucleic Acid Res. Mol. Biol. 73: 251-279.

Näär, A.M., Boutin, J.M., Lipkin, S.M., Yu, V.C., Holloway, J.M., Glass, C.K., and Rosenfeld, M.G. 1991. The orientation and spacing of core DNA-binding motifs dictate selective transcriptional responses to three nuclear receptors. Cell 65: $1267-1279$. 
Näär, A.M., Lemon, B.D., and Tjian, R. 2001. Transcriptional coactivator complexes. Annu. Rev. Biochem. 70: 475-501.

Nettles, K.W. and Greene, G.L. 2005. Ligand control of coregulator recruitment to nuclear receptors. Annu. Rev. Physiol. 67: 309-333.

Noel, J. and Turcotte, B. 1998. Zinc cluster proteins Leu3p and Uga3p recognize highly related but distinct DNA targets. J. Biol. Chem. 273: 17463-17468.

Oliver, B.G., Song, J.L., Choiniere, J.H., and White, T.C. 2007. cis-Acting elements within the Candida albicans ERG11 promoter mediate the azole response through transcription factor Upc2p. Eukaryot. Cell 6: 2231-2239.

Onate, S.A., Boonyaratanakornkit, V., Spencer, T.E., Tsai, S.Y., Tsai, M.J., Edwards, D.P., and O'Malley, B.W. 1998. The steroid receptor coactivator-1 contains multiple receptor interacting and activation domains that cooperatively enhance the activation function 1 (AF1) and AF2 domains of steroid receptors. J. Biol. Chem. 273: 12101-12108.

Owen, G.I. and Zelent, A. 2000. Origins and evolutionary diversification of the nuclear receptor superfamily. Cell. Mol. Life Sci. 57: 809-827.

Ozcan, S., Leong, T., and Johnston, M. 1996. Rgt1p of Saccharomyces cerevisiae, a key regulator of glucose-induced genes, is both an activator and a repressor of transcription. Mol. Cell. Biol. 16: 6419-6426.

Parks, D.J., Blanchard, S.G., Bledsoe, R.K., Chandra, G., Consler, T.G., Kliewer, S.A., Stimmel, J.B., Willson, T.M., Zavacki, A.M., Moore, D.D., et al. 1999. Bile acids: Natural ligands for an orphan nuclear receptor. Science 284: 1365-1368.

Patzold, A.J. and Lehming, N. 2001. Why Pprlp is a weak activator of transcription. FEBS Lett. 494: 64-68.

Peet, D.J., Janowski, B.A., and Mangelsdorf, D.J. 1998. The LXRs: A new class of oxysterol receptors. Curr. Opin. Genet. Dev. 8: 571-575.

Perlmann, T., Rangarajan, P.N., Umesono, K., and Evans, R.M. 1993. Determinants for selective RAR and TR recognition of direct repeat HREs. Genes \& Dev. 7: 1411-1422.

Pfeifer, K., Kim, K.S., Kogan, S., and Guarente, L. 1989. Functional dissection and sequence of yeast HAP1 activator. Cell 56: 291-301.

Phelps, C., Gburcik, V., Suslova, E., Dudek, P., Forafonov, F., Bot, N., MacLean, M., Fagan, R.J., and Picard, D. 2006. Fungi and animals may share a common ancestor to nuclear receptors. Proc. Natl. Acad. Sci. 103: 7077-7081.

Piddock, L.J. 2006. Multidrug-resistance efflux pumps-Not just for resistance. Nat. Rev. Microbiol. 4: 629-636.

Prezant, T., Pfeifer, K., and Guarente, L. 1987. Organization of the regulatory region of the yeast CYC7 gene: Multiple factors are involved in regulation. Mol. Cell. Biol. 7: 3252-3259.

Radhakrishnan, I., Perez-Alvarado, G.C., Parker, D., Dyson, H.J., Montminy, M.R., and Wright, P.E. 1997. Solution structure of the KIX domain of CBP bound to the transactivation domain of CREB: A model for activator:coactivator interactions. Cell 91: 741-752.

Raghuram, S., Stayrook, K.R., Huang, P., Rogers, P.M., Nosie, A.K., McClure, D.B., Burris, L.L., Khorasanizadeh, S., Burris, T.P., and Rastinejad, F. 2007. Identification of heme as the ligand for the orphan nuclear receptors REV-ERB $\alpha$ and REVERBß. Nat. Struct. Mol. Biol. 14: 1207-1213.

Ramakrishnan, S.N. and Muscat, G.E. 2006. The orphan Rev-erb nuclear receptors: A link between metabolism, circadian rhythm and inflammation? Nucl. Recept. Signal. 4: e009. doi: $10.1621 / \mathrm{nrs} .04009$.

Reece, R.J. 2000. Molecular basis of nutrient-controlled gene expression in Saccharomyces cerevisiae. Cell. Mol. Life Sci. 57: 1161-1171.
Reece, R.J. and Ptashne, M. 1993. Determinants of binding-site specificity among yeast C6 zinc cluster proteins. Science 261: 909-911.

Reece, R.J., Beynon, L., Holden, S., Hughes, A.D., Rebora, K., and Sellick, C.A. 2006. Nutrient-regulated gene expression in eukaryotes. Biochem. Soc. Symp. 73: 85-96.

Reeves, W.M. and Hahn, S. 2005. Targets of the Gal4 transcription activator in functional transcription complexes. Mol. Cell. Biol. 25: 9092-9102.

Reinking, J., Lam, M.M., Pardee, K., Sampson, H.M., Liu, S., Yang, P., Williams, S., White, W., Lajoie, G., Edwards, A., et al. 2005. The Drosophila nuclear receptor e75 contains heme and is gas responsive. Cell 122: 195-207.

Renaud, J.P., Harris, J.M., Downes, M., Burke, L.J., and Muscat, G.E. 2000. Structure-function analysis of the Rev-erbA and RVR ligand-binding domains reveals a large hydrophobic surface that mediates corepressor binding and a ligand cavity occupied by side chains. Mol. Endocrinol. 14: 700-717.

Robinson-Rechavi, M. and Laudet, V. 2003. Bioinformatics of nuclear receptors. Methods Enzymol. 364: 95-118.

Roeder, R.G. 1998. Role of general and gene-specific cofactors in the regulation of eukaryotic transcription. Cold Spring Harb. Symp. Quant. Biol. 63: 201-218.

Rogers, B., Decottignies, A., Kolaczkowski, M., Carvajal, E., Balzi, E., and Goffeau, A. 2001. The pleitropic drug ABC transporters from Saccharomyces cerevisiae. J. Mol. Microbiol. Biotechnol. 3: 207-214.

Rosenfeld, M.G. and Glass, C.K. 2001. Coregulator codes of transcriptional regulation by nuclear receptors. J. Biol. Chem. 276: 36865-36868.

Rosenfeld, M.G., Lunyak, V.V., and Glass, C.K. 2006. Sensors and signals: A coactivator/corepressor/epigenetic code for integrating signal-dependent programs of transcriptional response. Genes \& Dev. 20: 1405-1428.

Savkur, R.S. and Burris, T.P. 2004. The coactivator LXXLL nuclear receptor recognition motif. J. Pept. Res. 63: 207-212.

Schjerling, P. and Holmberg, S. 1996. Comparative amino acid sequence analysis of the C6 zinc cluster family of transcriptional regulators. Nucleic Acids Res. 24: 4599-4607.

Schwabe, J.W. and Rhodes, D. 1991. Beyond zinc fingers: Steroid hormone receptors have a novel structural motif for DNA recognition. Trends Biochem. Sci. 16: 291-296.

Sellick, C.A. and Reece, R.J. 2003. Modulation of transcription factor function by an amino acid: Activation of Put3p by proline. EMBO J. 22: 5147-5153.

Sellick, C.A. and Reece, R.J. 2005. Eukaryotic transcription factors as direct nutrient sensors. Trends Biochem. Sci. 30: 405-412.

Sipos, G. and Kuchler, K. 2006. Fungal ATP-binding cassette $(\mathrm{ABC})$ transporters in drug resistance \& detoxification. Curr. Drug Targets 7: 471-481.

Smith, S.J., Crowley, J.H., and Parks, L.W. 1996. Transcriptional regulation by ergosterol in the yeast Saccharomyces cerevisiae. Mol. Cell. Biol. 16: 5427-5432.

Suzuki, Y., Nogi, Y., Abe, A., and Fukasawa, T. 1988. GAL11 protein, an auxiliary transcription activator for genes encoding galactose-metabolizing enzymes in Saccharomyces cerevisiae. Mol. Cell. Biol. 8: 4991-4999.

Szakacs, G., Paterson, J.K., Ludwig, J.A., Booth-Genthe, C., and Gottesman, M.M. 2006. Targeting multidrug resistance in cancer. Nat. Rev. Drug Discov. 5: 219-234.

Taubert, S., Van Gilst, M.R., Hansen, M., and Yamamoto, K.R. 2006. A Mediator subunit, MDT-15, integrates regulation of fatty acid metabolism by NHR-49-dependent and -independent pathways in C. elegans. Genes \& Dev. 20: 1137-1149.

Taubert, S., Hansen, M., Van Gilst, M.R., Cooper, S.B., and Yamamoto, K.R. 2008. The Mediator subunit MDT-15 con- 
fers metabolic adaptation to ingested material. PLoS Genet. 4: e1000021. doi: 10.1371/journal.pgen.1000021.

Thakur, J.K., Arthanari, H., Yang, F., Pan, S.J., Fan, X., Breger, J., Frueh, D.P., Gulshan, K., Li, D.K., Mylonakis, E., et al. 2008a. A nuclear receptor-like pathway regulating multidrug resistance in fungi. Nature 452: 604-609.

Thakur, J.K., Arthanari, H., Yang, F., Chau, K.H., Wagner, G., and Näär, A.M. 2008b. Mediator subunit Gall1p/MED15 is required for fatty acid-dependent gene activation by yeast transcription factor Oaflp. J. Biol. Chem. doi: 10.1074/jbc. M808263200.

Todd, R.B. and Andrianopoulos, A. 1997. Evolution of a fungal regulatory gene family: The $\mathrm{Zn}(\mathrm{II}) 2 \mathrm{Cys} 6$ binuclear cluster DNA binding motif. Fungal Genet. Biol. 21: 388-405.

Traven, A., Jelicic, B., and Sopta, M. 2006. Yeast Gal4: A transcriptional paradigm revisited. EMBO Rep. 7: 496-499.

Tsai, H.F., Krol, A.A., Sarti, K.E., and Bennett, J.E. 2006. Candida glabrata PDR1, a transcriptional regulator of a pleiotropic drug resistance network, mediates azole resistance in clinical isolates and petite mutants. Antimicrob. Agents Chemother. 50: 1384-1392.

Umesono, K., Murakami, K.K., Thompson, C.C., and Evans, R.M. 1991. Direct repeats as selective response elements for the thyroid hormone, retinoic acid, and vitamin D3 receptors. Cell 65: 1255-1266.

Vermitsky, J.P. and Edlind, T.D. 2004. Azole resistance in Candida glabrata: Coordinate upregulation of multidrug transporters and evidence for a Pdr1-like transcription factor. Antimicrob. Agents Chemother. 48: 3773-3781.

Vermitsky, J.P., Earhart, K.D., Smith, W.L., Homayouni, R., Edlind, T.D., and Rogers, P.D. 2006. Pdr1 regulates multidrug resistance in Candida glabrata: Gene disruption and genomewide expression studies. Mol. Microbiol. 61: 704-722.

Vik, A. and Rine, J. 2001. Upc2p and Ecm22p, dual regulators of sterol biosynthesis in Saccharomyces cerevisiae. Mol. Cell. Biol. 21: 6395-6405.

Watkins, R.E., Wisely, G.B., Moore, L.B., Collins, J.L., Lambert, M.H., Williams, S.P., Willson, T.M., Kliewer, S.A., and Redinbo, M.R. 2001. The human nuclear xenobiotic receptor PXR: Structural determinants of directed promiscuity. Science 292: 2329-2333.

Weatherman, R.V., Fletterick, R.J., and Scanlan, T.S. 1999. Nuclear-receptor ligands and ligand-binding domains. Annu. Rev. Biochem. 68: 559-581.

Weis, K.E., Ekena, K., Thomas, J.A., Lazennec, G., and Katzenellenbogen, B.S. 1996. Constitutively active human estrogen receptors containing amino acid substitutions for tyrosine 537 in the receptor protein. Mol. Endocrinol. 10: 1388-1398.

Willson, T.M. and Kliewer, S.A. 2002. PXR, CAR and drug metabolism. Nat. Rev. Drug Discov. 1: 259-266.

Xu, H.E., Lambert, M.H., Montana, V.G., Parks, D.J., Blanchard, S.G., Brown, P.J., Sternbach, D.D., Lehmann, J.M., Wisely, G.B., Willson, T.M., et al. 1999. Molecular recognition of fatty acids by peroxisome proliferator-activated receptors. Mol. Cell 3: 397-403.

Yang, F., Vought, B.W., Satterlee, J.S., Walker, A.K., Sun, Z.Y., Watts, J.L., DeBeaumont, R., Saito, R.M., Hyberts, S.G., Yang, S., et al. 2006. An ARC/Mediator subunit required for SREBP control of cholesterol and lipid homeostasis. Nature 442: 700-704.

Yin, L., Wu, N., Curtin, J.C., Qatanani, M., Szwergold, N.R., Reid, R.A., Waitt, G.M., Parks, D.J., Pearce, K.H., Wisely, G.B., et al. 2007. Rev-erb $\alpha$, a heme sensor that coordinates metabolic and circadian pathways. Science 318: 1786-1789.

Zamir, I., Harding, H.P., Atkins, G.B., Horlein, A., Glass, C.K., Rosenfeld, M.G., and Lazar, M.A. 1996. A nuclear hormone receptor corepressor mediates transcriptional silencing by receptors with distinct repression domains. Mol. Cell. Biol. 16: 5458-5465.

Zhang, L. and Guarente, L. 1995. Heme binds to a short sequence that serves a regulatory function in diverse proteins. EMBO I. 14: 313-320.

Zhang, L. and Hach, A. 1999. Molecular mechanism of heme signaling in yeast: The transcriptional activator Hap1 serves as the key mediator. Cell. Mol. Life Sci. 56: 415-426.

Znaidi, S., Weber, S., Al-Abdin, O.Z., Bomme, P., Saidane, S., Drouin, S., Lemieux, S., De Deken, X., Robert, F., and Raymond, M. 2008. Genomewide location analysis of Candida albicans Upc2p, a regulator of sterol metabolism and azole drug resistance. Eukaryot. Cell 7: 836-847. 


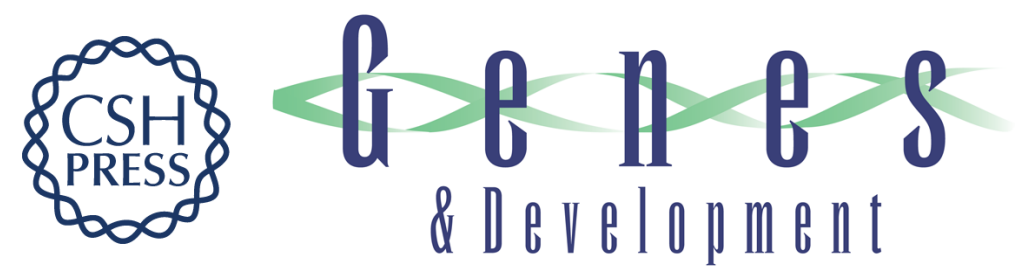

\section{Nuclear receptor-like transcription factors in fungi}

Anders M. Näär and Jitendra K. Thakur

Genes Dev. 2009, 23:

Access the most recent version at doi:10.1101/gad.1743009

References This article cites 149 articles, 59 of which can be accessed free at: http://genesdev.cshlp.org/content/23/4/419.full.html\#ref-list-1

License

Email Alerting Receive free email alerts when new articles cite this article - sign up in the box at the top Service right corner of the article or click here.

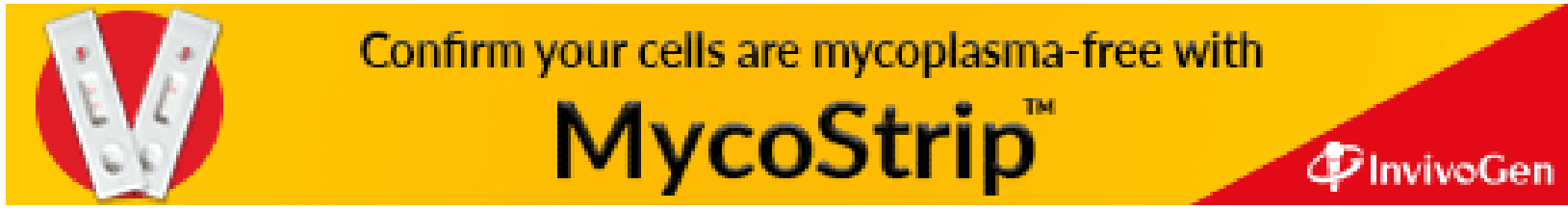

